\title{
N-acetyl-seryl-aspartyl-lysyl-proline Inhibits Diabetes-Associated Kidney Fibrosis and Endothelial-Mesenchymal Transition
}

\author{
Takako Nagai, ${ }^{1}$ Megumi Kanasaki, ${ }^{1}$ Swayam Prakash Srivastava, ${ }^{1}$ Yuka Nakamura, \\ Yasuhito Ishigaki, ${ }^{2}$ Munehiro Kitada, ${ }^{1}$ Sen Shi, ${ }^{1}$ Keizo Kanasaki, ${ }^{1}$ and Daisuke Koya ${ }^{1}$ \\ ${ }^{1}$ Department of Diabetology and Endocrinology, Kanazawa Medical University, Uchinada, Ishikawa 920-0293, Japan \\ ${ }^{2}$ Medical Research Institute, Kanazawa Medical University, Uchinada, Ishikawa 920-0293, Japan \\ Correspondence should be addressed to Keizo Kanasaki; kkanasak@kanazawa-med.ac.jp \\ and Daisuke Koya; koya0516@kanazawa-med.ac.jp
}

Received 18 December 2013; Accepted 26 January 2014; Published 24 March 2014

Academic Editor: Gangadhar Taduri

Copyright (C) 2014 Takako Nagai et al. This is an open access article distributed under the Creative Commons Attribution License, which permits unrestricted use, distribution, and reproduction in any medium, provided the original work is properly cited.

\begin{abstract}
Endothelial-to-mesenchymal transition (EndMT) emerges as an important source of fibroblasts. MicroRNA let-7 exhibits antiEndMT effects and fibroblast growth factor (FGF) receptor has been shown to be an important in microRNA let-7 expression. The endogenous antifibrotic peptide $\mathrm{N}$-acetyl-seryl-aspartyl-lysyl-proline (AcSDKP) is a substrate of angiotensin-converting enzyme (ACE). Here, we found that AcSDKP inhibited the EndMT and exhibited fibrotic effects that were associated with FGF receptormediated anti-fibrotic program. Conventional ACE inhibitor plus AcSDKP ameliorated kidney fibrosis and inhibited EndMT compared to therapy with the ACE inhibitor alone in diabetic CD-1 mice. The endogenous AcSDKP levels were suppressed in diabetic animals. Cytokines induced cultured endothelial cells into EndMT; coincubation with AcSDKP inhibited EndMT. Expression of microRNA let-7 family was suppressed in the diabetic kidney; antifibrotic and anti-EndMT effects of AcSDKP were associated with the restoration of microRNA let-7 levels. AcSDKP restored diabetes- or cytokines-suppressed FGF receptor expression/phosphorylation into normal levels both in vivo and in vitro. These results suggest that AcSDKP is an endogenous antifibrotic molecule that has the potential to cure diabetic kidney fibrosis via an inhibition of the EndMT associated with the restoration of FGF receptor and microRNA let-7.
\end{abstract}

\section{Introduction}

Diabetic nephropathy is leading course of end-stage kidney disease and kidney fibrosis is the final common pathway in progressive kidney diseases. The fibroblasts that play a role in kidney fibrosis are believed to be heterogeneous [1]. Recently, the endothelial-to-mesenchymal transition (EndMT) has emerged as an important source of myofibroblasts or activated fibroblasts [2].

$\mathrm{N}$-acetyl-seryl-aspartyl-lysyl-proline (AcSDKP) is a tetrapeptide that is normally present in human plasma and is hydrolyzed by angiotensin-converting enzyme (ACE); ACEinhibitor (ACE-I) treatment increases the plasma level of AcSDKP by fivefold [3]. We demonstrated that AcSDKP has an antifibrotic activity; that is, AcSDKP inhibits the transforming growth factor (TGF)- $\beta$-induced fibrogenic gene expression in human mesangial cells by inhibiting the smad $2 / 3$ signaling [4] and rescues glomerular damage in $\mathrm{db} / \mathrm{db}$ mice [5]. AcSDKP reportedly exhibits antifibrotic and organ protective effects in various experimental models [6-14].

We aimed to investigate whether antifibrotic peptide AcSDKP exerts additive antifibrotic effects associated with the inhibition of EndMT on top of the conventional ACE-I based therapy in fibrotic kidney model of diabetic mice.

\section{Materials and Methods}

2.1. Reagents and Antibodies. The AcSDKP was a gift from Dr. Omata from Asabio Bio Technology (Osaka, Japan). Imidapril (ACE-I) and TA-606 (ARB) were provided by 
Mitsubishi Tanabe Pharma (Osaka Japan) through an MTA agreement. The mouse monoclonal anti-human CD31 antibody was purchased from R\&D Systems (Minneapolis, MN, USA), and the rat polyclonal anti-mouse CD31 antibody was purchased from EMFRET Analytics $\mathrm{GmbH}$ \& Co. KG (Eibelstadt, Germany). The polyclonal rabbit anti- $\alpha$ SMA antibody was obtained from Gene Tex (Irvine, CA, USA). The rabbit polyclonal anti-SM22 $\alpha$ antibody and monoclonal antiVE-cadherin antibody were obtained from Novus Biological (Littleton, CO, USA). The polyclonal anti-GAPDH and antiTGF- $\beta$-receptor I antibodies were obtained from SigmaAldrich (St. Louis, MO, USA). Fluorescein-, rhodamine-, and Alexa 647-conjugated secondary antibodies were obtained from Jackson ImmunoResearch (West Grove, PA, USA). Antifibroblast growth factor (FGF) receptor, anti-phosphoFGF receptor, and the HRP-conjugated secondary antibodies for Western blot detection were purchased from Cell Signaling Technology (Danvers, MA, USA). TGF- $\beta 2$, tumor necrosis factor (TNF) $-\alpha$, and interleukin (IL)- $1 \beta$ were purchased from PeproTech (Rocky Hill, NJ, USA).

2.2. Animal Experiments. We utilized a fibrotic diabetic kidney disease model, that is, streptozotocin- (STZ-) treated CD1 mice [15]. Eight-week-old male CD-1 mice were obtained from Sankyo Lab Service (Tokyo, Japan). A single intraperitoneal injection of streptozotocin (STZ) $(200 \mathrm{mg} / \mathrm{kg})$ was given to the mice. We confirmed the induction of diabetes by a blood glucose level $>16 \mathrm{mM}$ at 2 weeks after the STZ injection. Sixteen weeks after the induction of diabetes, the diabetic mice were divided into the following four groups: (imidapril [2.5 mg/kg BW/day], AcSDKP [500 $\mu \mathrm{g} / \mathrm{kg} \mathrm{BW/day}$ using an osmotic mini-pump], AcSDKP+imidapril, TA-606 [3 $\mathrm{mg} / \mathrm{kg}$ BW/day], and nontreatment). Imidapril or TA606 was provided in drinking water. All of the mice were euthanized 24 weeks after the induction of diabetes, and their blood pressure was monitored using the tail-cuff method with a BP-98A instrument (Softron Co. Beijing, China) within a week before euthanasia.

2.3. AcSDKP Measurements. Blood was harvested into a heparinized tube containing captopril (final concentration $10 \mu \mathrm{mol} / \mathrm{L}$ ) and centrifuged at $3,000 \times \mathrm{g}$ for $15 \mathrm{~min}$ at $4^{\circ} \mathrm{C}$. We obtained estimated plasma and urine Ac-SDKP concentrations using a competitive enzyme immunoassay kit (SPI-BIO, Massy, France) according to the manufacturer's instruction. Urine AcSDKP was normalized at the urine creatinine level.

2.4. EndMT Detection In Vivo. EndMT were determined by double-labeling with antibodies against $\mathrm{CD} 31$ and $\alpha \mathrm{SMA}$, or with antibodies against CD31 and FSP1 on frozen sections (5$\mu \mathrm{m})$. The immunolabeled sections were analyzed using fluorescence microscopy (Axio Vert.A1, Carl Zeiss Microscopy $\mathrm{GmbH}$, Jena, Germany). We obtained images of six different fields of view at 300x magnification and performed quantification. All immunolabelings were analyzed with appropriate negative control, including isotype IgG.
2.5. Morphological Evaluation. We determined the surface area of 10 glomeruli in each mouse using ImageJ software. A point-counting method was utilized to evaluate the relative area of the mesangial matrix (\%). We analyzed 10 PAS-stained glomeruli from each mouse using a digital microscope screen grid containing $540(27 \times 20)$ points and employing Adobe Photoshop Element 6.0. The number of grid points on the mesangial tissue was divided by the total number of points in the glomerulus to obtain the mesangial area in a given glomerulus as the percentage of the total area of the glomerulus. Images of Masson's trichrome-stained tissue were analyzed using ImageJ software, and the fibrotic areas were quantified. For each mouse, images of six different fields of view at 100x magnification were evaluated.

2.6. In Vitro EndMT. Human umbilical vein endothelial cells (HUVEC) (Kurabo Industries Ltd., Osaka, Japan) cultured in HuMedia-EG2 medium and human dermal microvascular endothelial cells (HMVEC) (Lonza, Basel, Switzerland) cultured in EGM medium were used for the experiments. When cells grown on an adhesion reagent (Kurabo Medical, Osaka, Japan) reached $70 \%$ confluence, a combination of TGF- $\beta 2$ $(2.5 \mathrm{ng} / \mathrm{mL}), \mathrm{TNF}-\alpha(1.0 \mathrm{ng} / \mathrm{mL})$, and IL- $1 \beta(2.0 \mathrm{ng} / \mathrm{mL})$ was added to the experimental medium (a mixture of HumediaEG2 in serum-free RPMI, 1:3 ratio) for an indicated interval, with or without a $2 \mathrm{~h}$ preincubation in AcSDKP $(100 \mathrm{nM})$.

2.7. Western Blotting. Protein lysates were denatured in a SDS sample buffer at $100^{\circ} \mathrm{C}$ for $5 \mathrm{~min}$. After centrifugation $\left(17,000 \times \mathrm{g}\right.$ for $10 \mathrm{~min}$ at $\left.4^{\circ} \mathrm{C}\right)$, supernatants were separated on SDS-polyacrylamide gels and blotted onto PVDF membranes (Pall Corporation, Pensacola, FL, USA) using the semidry method. The immunoreactive bands were developed using an enhanced chemiluminescence (ECL) detection system (Pierce Biotechnology, Rockford, IL, USA) and detected using an ImageQuant LAS 400 digital biomolecular imaging system (GE Healthcare Life Sciences, Uppsala, Sweden).

2.8. MicroRNA Array Analysis. Total RNA was isolated using a miRNeasy kit (Qiagen). After dephosphorylation and denaturation, the total RNA was labeled with cyanine 3-pCp and subsequently hybridized to an Agilent mouse microRNA microarray (release version 15) using the microRNA Complete Labeling and Hyb Kit (Agilent Technologies, Inc.). After hybridization for $20 \mathrm{~h}$, the slides were washed using the Gene Expression Wash Buffer (Agilent Technologies, Inc.), scanned using an Agilent Scanner G2565BA, and processed and analyzed using Agilent Feature Extraction Software version 9.5.1. The raw data were analyzed using GeneSpring GX software version 12.5 (Agilent Technologies, Inc.).

2.9. MicroRNA Isolation and $q P C R$. The kidney tissues that had been maintained at $-80^{\circ} \mathrm{C}$ were first incubated in RNAlater ${ }^{R}$-ICE (Life Technologies) for $16 \mathrm{~h}$ at $-20^{\circ} \mathrm{C}$ before homogenization. The tissues were homogenized on ice and the microRNA was extracted. Total cDNA was synthesized 


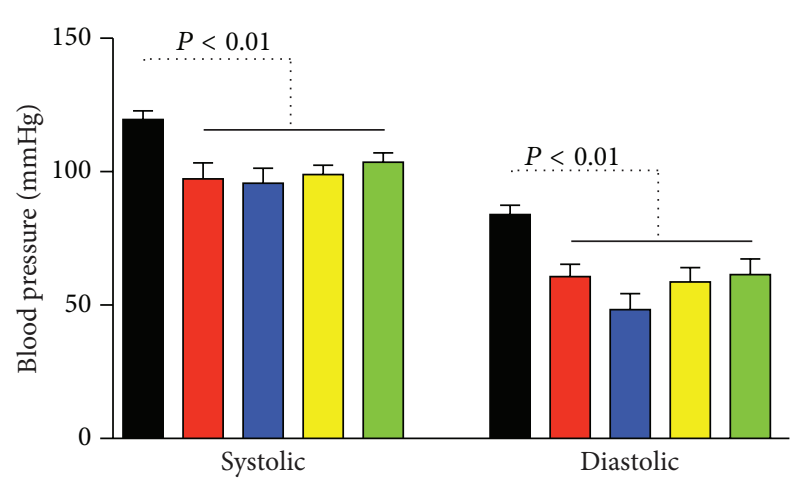

(a)

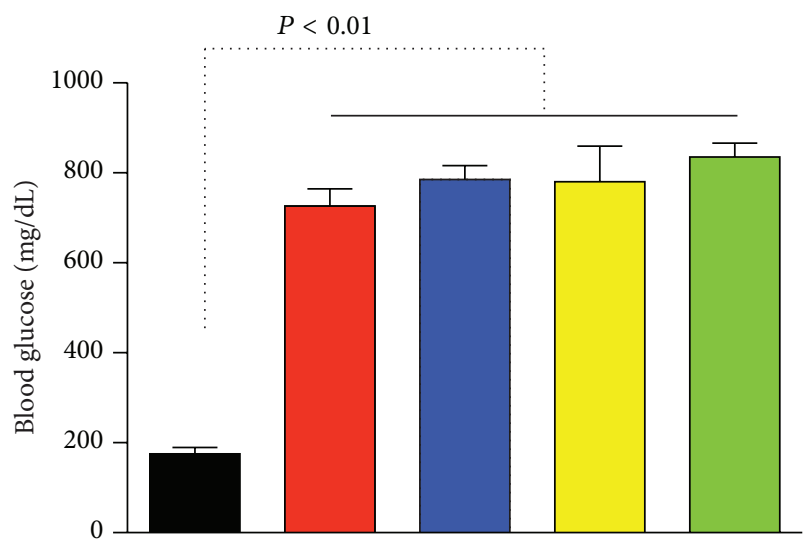

(c)

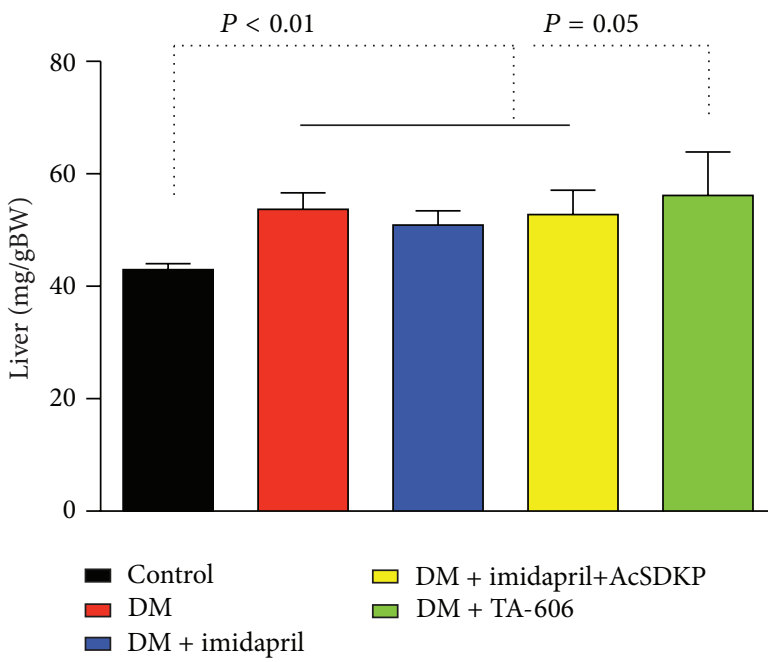

(e)

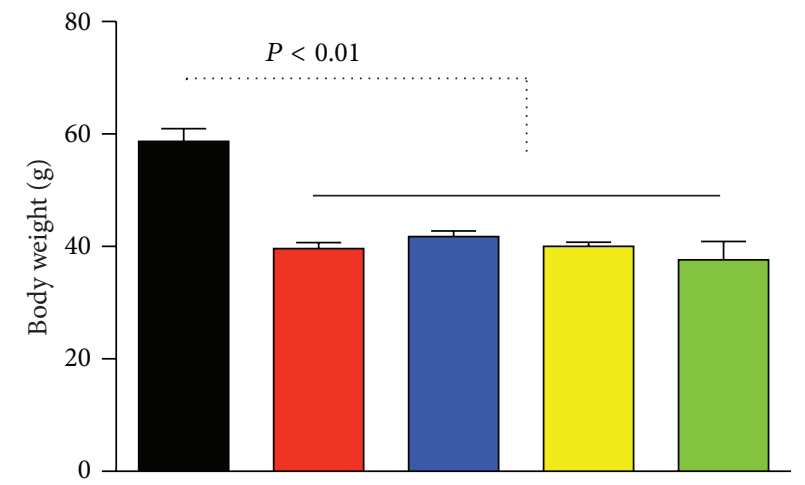

(b)

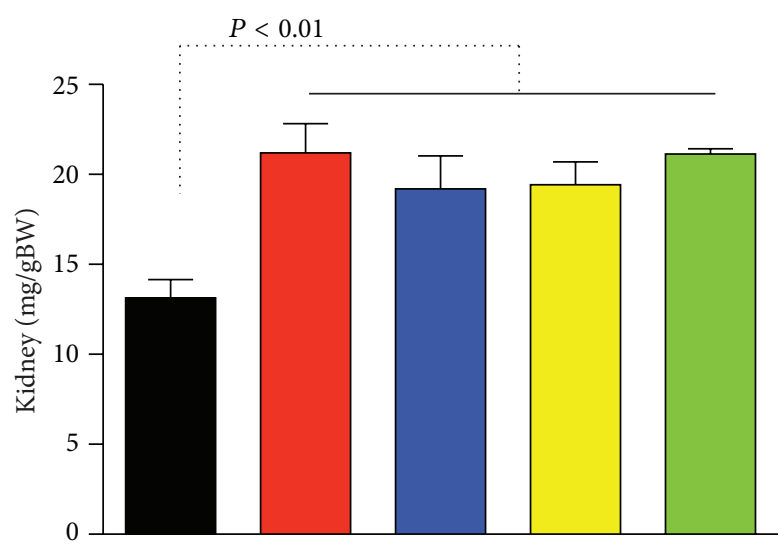

(d)

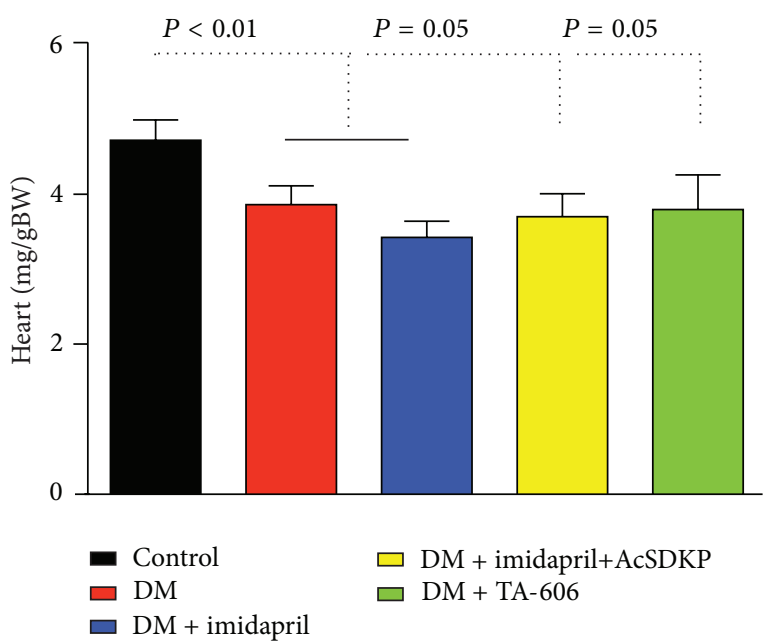

(f)

FiguRE 1: Characteristics of the experimental animals. (a) Blood pressure was measured within 1 week before the mice were euthanized. (b) Body weight. (c) Blood glucose level at the time of euthanasia. (d-f) Organ weights. Kidney (d), liver (e), and heart (f) weights relative to body weight $(\mathrm{g})$ are shown. The data are expressed as the mean \pm SEM values. Control: $n=7$, STZ-induced diabetes: $n=5$, diabetes treated with imidapril: $n=6$, diabetes treated with imidapril+AcSDKP: $n=5$, diabetes treated with TA-606: $n=3$. Diabetic mice are designated as DM. 


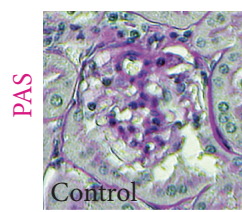

(a)

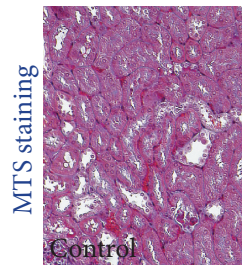

(f)

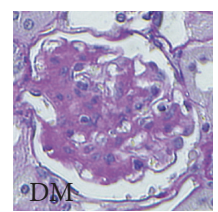

(b)



(g)

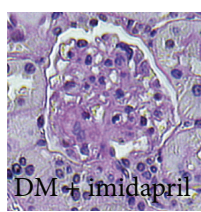

(c)

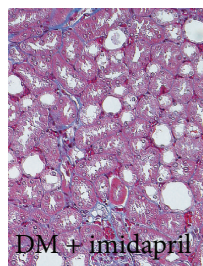

(h)



(d)

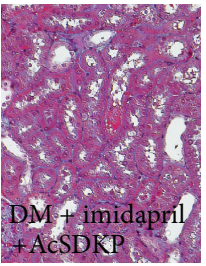

(i)



(e)

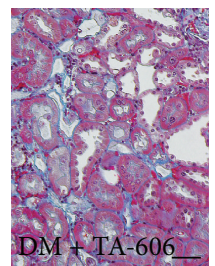

(j)

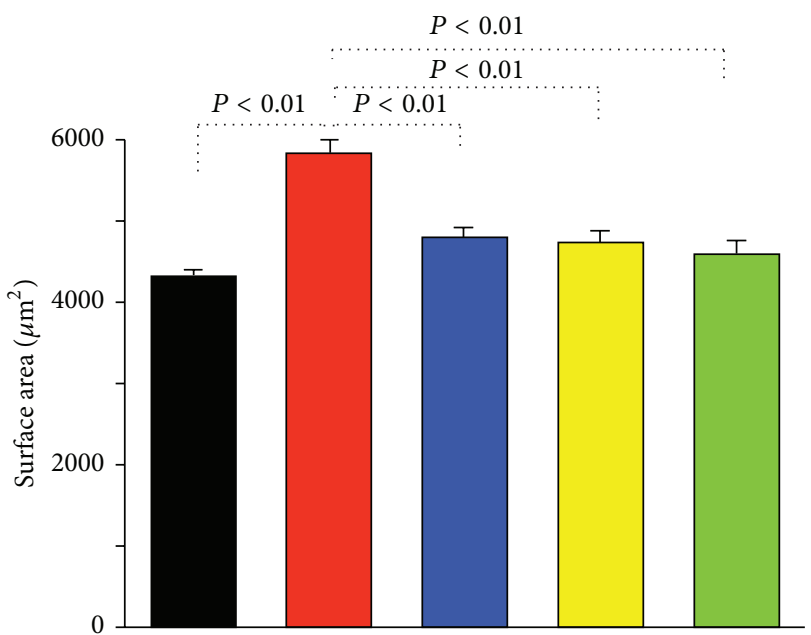

(k)

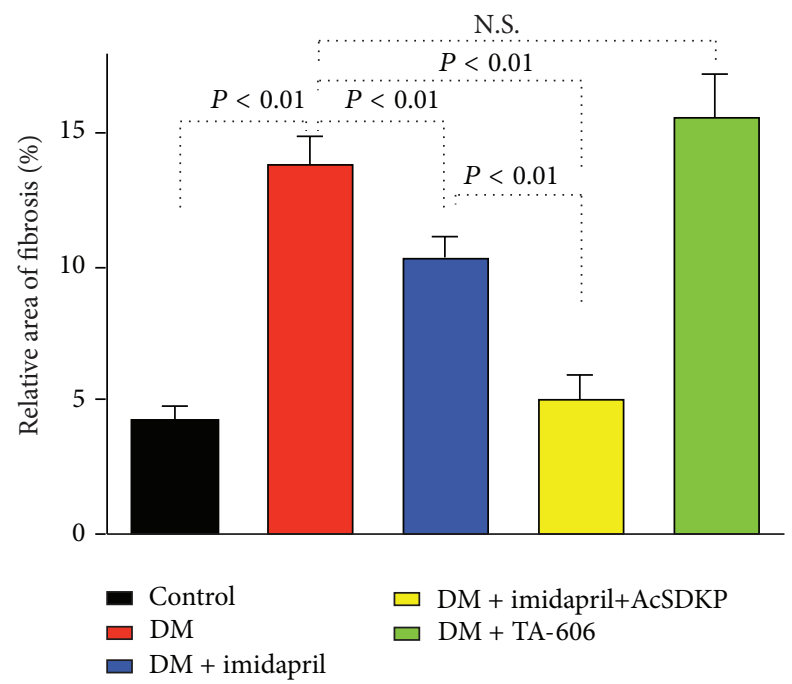

(m)

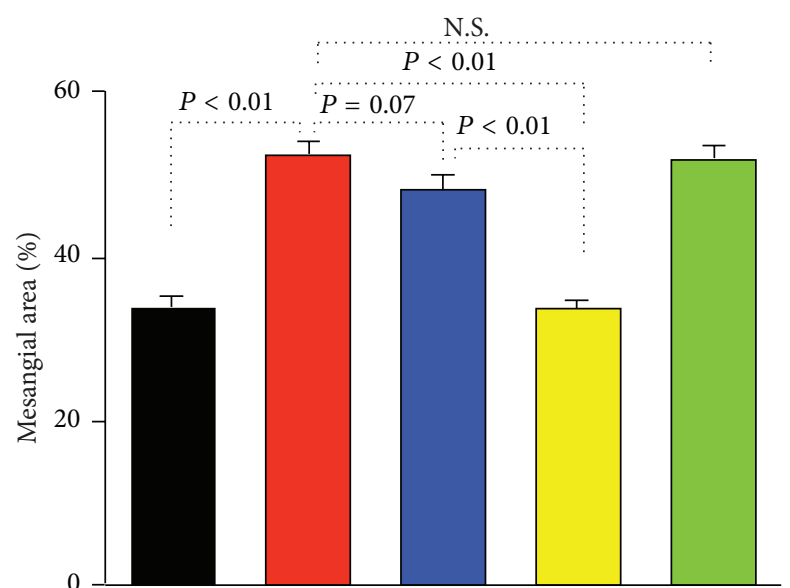

(1)

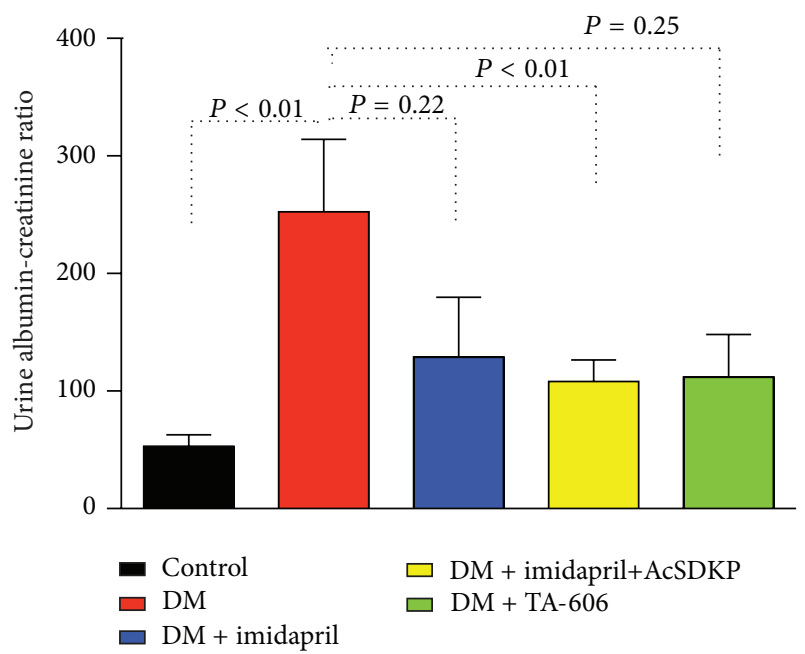

(n)

FIGURE 2: AcSDKP exerts antifibrotic effects on diabetic kidney disease. ((a)-(e)) Representative periodic acid Schiff- (PAS-) stained kidney samples from the indicated groups of mice. The original magnification of the images was 300x. ((f)-(j)) Representative images of Masson's trichrome-stained (MTS) samples from the indicated groups of mice are shown. The original magnification of the images was 200x. ((k)(m)) Morphometric analysis. The glomerular surface area $(\mathrm{k})$, relative mesangial area $(\mathrm{l})$, and relative area of fibrosis $(\mathrm{m})$ were analyzed by the method described in the Methods section. (n) Urinary albumin/creatinine ratio. The data are expressed as the mean \pm SEM values. Control: $n=7$, STZ-induced diabetes: $n=5$, diabetes treated with imidapril: $n=6$, diabetes treated with imidapril+AcSDKP: $n=5$, diabetes treated with TA-606: $n=3$. Diabetic mice are designated as DM. Scale bar: $50 \mu \mathrm{m}$. 




(a)

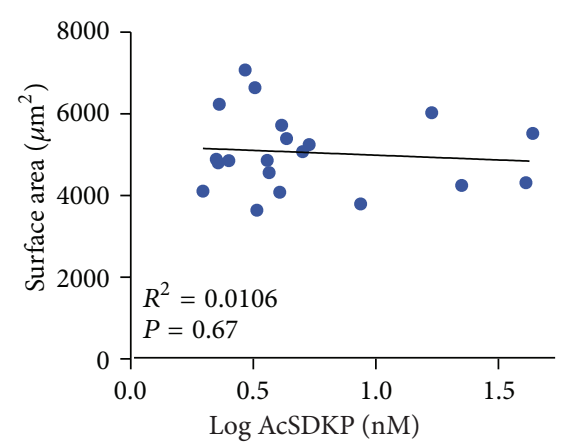

(c)

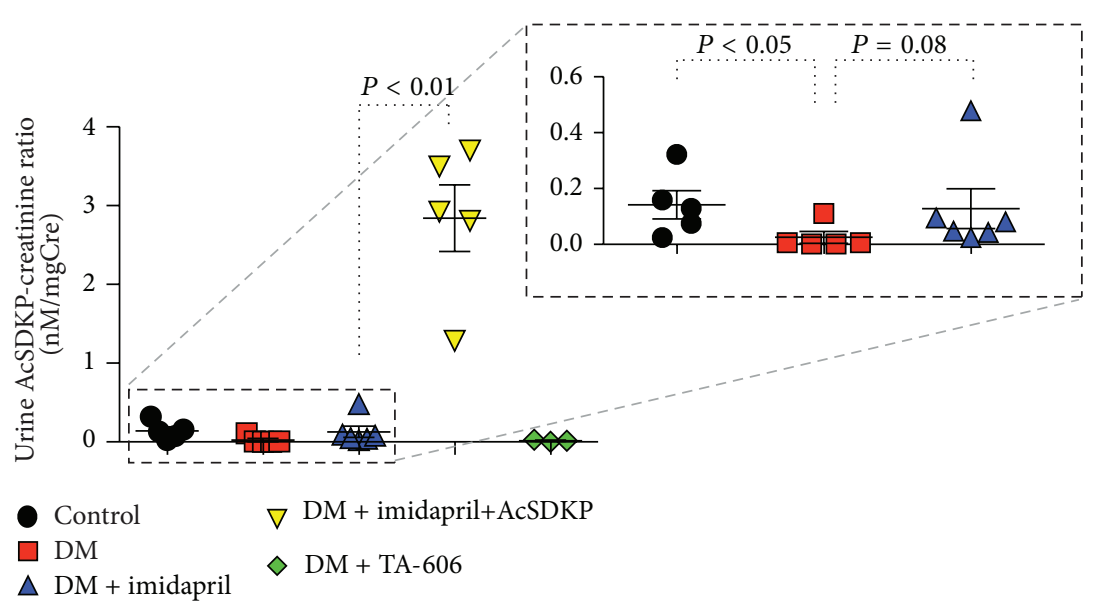

(b)

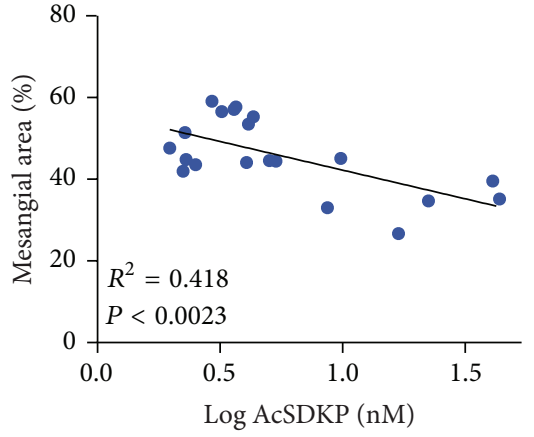

(d)



(e)

Figure 3: Negative correlation between the concentration of AcSDKP and mesangial area or relative fibrosis area. (a) Plasma concentration of AcSDKP in the indicated group of mice. (b) Urinary AcSDKP/creatinine ratio. Inset in (b) shows an enlargement of the dotted square area of the graph. The data are expressed as the mean \pm SEM values. Diabetes is designated as DM. Control: $n=7$ (urine, $n=5$ ), STZ-induced diabetes: $n=5$, diabetes treated with imidapril: $n=6$, diabetes treated with imidapril+AcSDKP: $n=5$, diabetes treated with TA-606: $n=3$. ((c)-(e)) Linear regression analysis of the relationship between the plasma AcSDKP concentration and the values for the morphometric parameters. Glomerular surface area (c), relative mesangial area (d), and relative fibrosis area (e) are shown. The AcSDKP levels were plotted using a log conversion. Only diabetic animals were analyzed.

using a miScript II RT kit (Qiagen) and the real-time quantification of microRNA expression was performed using a miScript SYBR Green PCR kit (Qiagen). Samples of 3 ng of cDNA were used in the qPCR experiment. The primers for Mm_let7f-1, Mm_let-7 g-1, and Mm_let-7i-1 were from the miScript Primer Assay designed by Qiagen. The mature microRNA sequences were $5^{\prime}$ CUAUACAAUCUAUUGCCUUCCC for Mm_let-7f-1, 5' ACUGUACAGGCCACUGCCUUGC for Mm_let-7 g-1, and 5'CUGCGCAAGCUACUGCCUUGCU for Mm_let-7i-1. All of the experiments were performed in triplicate, and Hs_RNU6-2_1 (Qiagen) was used as an endogenous control for normalization.

2.10. Statistical Analysis. The data are expressed as the mean \pm SEM values. The Mann-Whitney $U$-test was used to determine the significance. Statistical significance was defined as $P<0.05$. GraphPad Prism software (ver. 5.0f) was used for the statistical analyses.

\section{Results}

3.1. Antifibrotic Effect of AcSDKP on the Top of ACE-I. The characteristics of the mice in each group are shown in Figure 1. Compared to the control mice, the diabetic mice had lower blood pressure, weighed less, and had higher blood glucose; their kidneys and livers weighed more, and their hearts weighed less. Treatment with imidapril, imidapril+AcSDKP, or the angiotensin II receptor blocker (ARB) TA-606 [16] did not alter the blood pressure, body weight, or organ weights of the diabetic mice (Figure 1).

The diabetic CD-1 mice exhibited glomerulomegaly and the accumulation of a PAS-positive matrix in the glomeruli (Figures 2(a), 2(b), 2(k), and 2(l)). Imidapril, imidapril+AcSDKP, and TA-606 inhibited the expansion of the glomerular surface area (Figures 2(b), 2(c), 2(d), $2(\mathrm{e})$, and $2(\mathrm{k}))$. The expansion of the mesangial area was partially inhibited by treatment with imidapril, and imidapril+AcSDKP treatment nearly completely inhibited the 


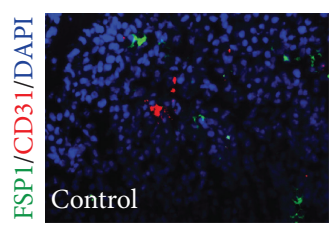

(a)

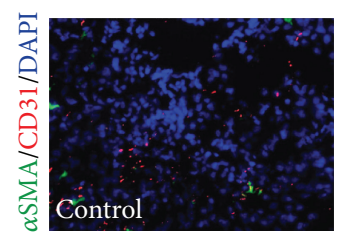

(f)



(b)

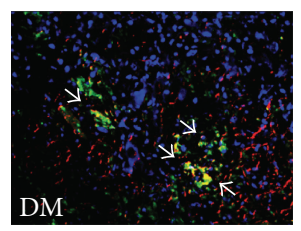

(g)

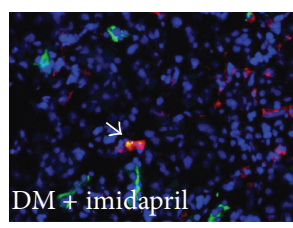

(c)

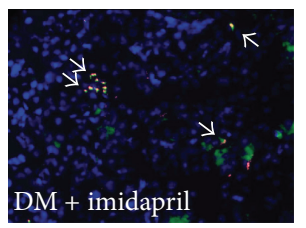

(h)

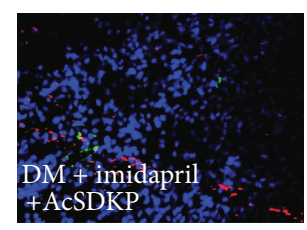

(d)

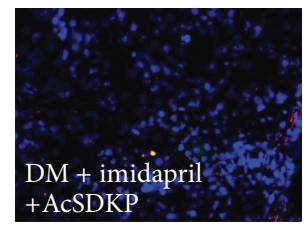

(i)

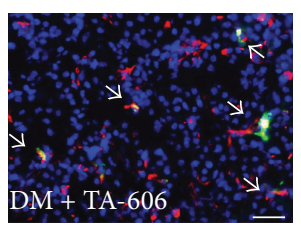

(e)

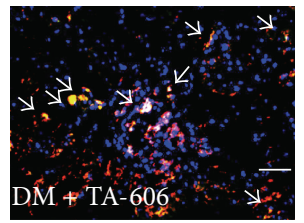

(j)

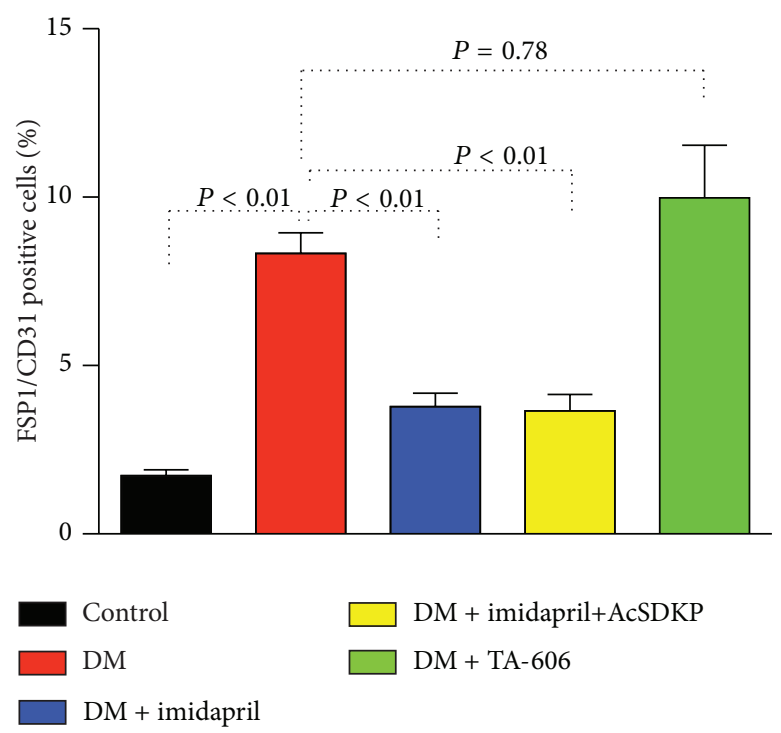

(k)

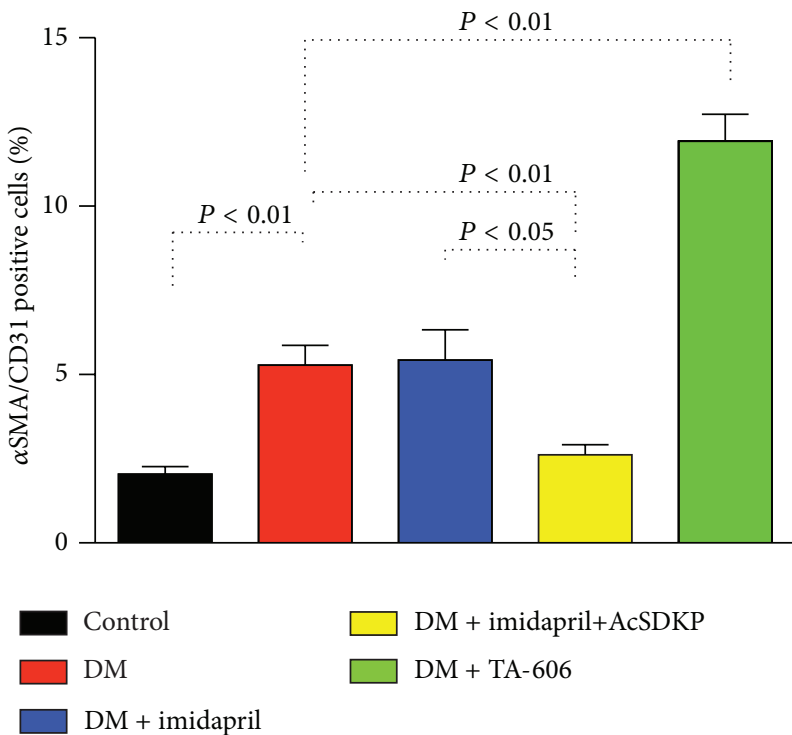

(1)

FIGURE 4: AcSDKP inhibits EndMT in the diabetic kidney. ((a)-(e)) Immunolabeling for FSP1 and CD31 in a kidney from each group of mice. Arrows indicate cells that are double-labeled for FSP1 and CD31. ((f)-(j)) Immunolabeling for $\alpha$ SMA and CD31 in a kidney from each group of mice. Arrows indicate cells that are double-labeled for $\alpha$ SMA and CD31. Merged images with DAPI-stained nuclei are shown. Scale bar: $25 \mu \mathrm{m}$. ((k), (l)) Quantification of cells undergoing EndMT. FSP1 and CD31 double-labeled cells (k) and $\alpha$ SMA and CD31 double-labeled cells (l) in each visual field were imaged using fluorescence microscopy and quantified. The data are expressed as the mean \pm SEM values. Diabetes is designated as DM. For all of the groups except the group that received TA-606 $(n=3), n=5$ mice were analyzed.

matrix expansion (Figures 2(b), 2(c), 2(d), and 2(l)). However, TA-606 did not inhibit the expansion of the mesangial area in the diabetic kidney (Figures 2(b), 2(e), and 2(1)).

MTS staining revealed massive tubulointerstitial fibrosis in the diabetic mice that was not exhibited in the control mice (Figures 2(f), 2(g), and 2(m)). A comparison to the untreated diabetic mice showed that imidapril partially decreased interstitial fibrosis (Figures 2(g), 2(h), and 2(m)) and that imidapril+AcSDKP combination nearly completely inhibited the interstitial fibrosis (Figures 2(g), 2(i), and 2(m)). However, TA-606 treatment did not suppress kidney fibrosis (Figures 2(g), 2(h), 2(i), 2(j), and $2(\mathrm{~m}))$. Compared to the control mice, the diabetic mice exhibited enhanced urinary albumin excretion (Figure 2(n)). Imidapril and TA-606 treatment inhibited the trend of increased urinary albumin excretion;
imidapril+AcSDKP significantly inhibited urine albumin excretion in the diabetic mice (Figure 2(n)).

3.2. The Levels of AcSDKP and Kidney Fibrosis. The plasma AcSDKP concentration demonstrated a decreased trend in the diabetic mice (Figure 3(a)). The AcSDKP concentration was high in the mice treated with imidapril (Figure 3(a): $P=0.05)$. When AcSDKP was added to the imidapril treatment, the concentration of AcSDKP was additionally increased by 5.5 -fold (Figure 3(a)). The mice treated with AcSDKP alone exhibited several antifibrotic effects of diabetic mice and displayed higher plasma levels of AcSDKP compared to the diabetic mice, as shown in several fibrotic animal models (see Supplementary Figure 1 available online at http://dx.doi.org/10.1155/2014/696475) [6-14]. The ratio of 




(a)

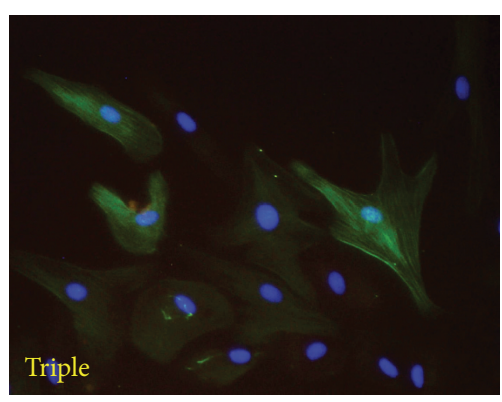

(b)



(c)

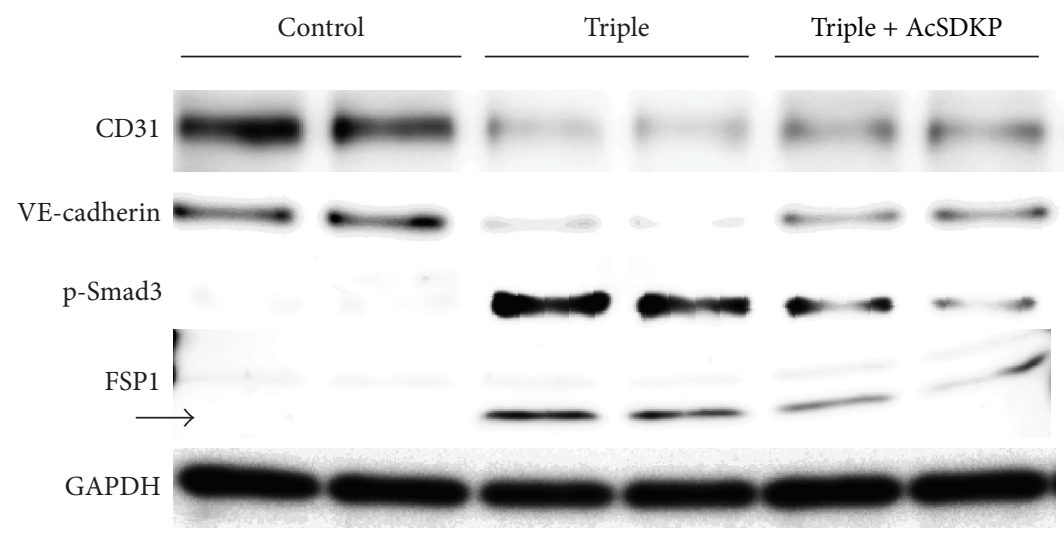

(d)

FIgURE 5: AcSDKP inhibits EndMT in vitro. HMVEC were exposed to a combination of cytokines (TGF- $\beta 2$ at $2.5 \mathrm{ng} / \mathrm{mL}, \mathrm{IL}-1 \beta$ at $4 \mathrm{ng} / \mathrm{mL}$, and TNF- $\alpha$ at $2 \mathrm{ng} / \mathrm{mL}$ ) in the presence or absence of AcSDKP $(100 \mathrm{nM})$ for $72 \mathrm{~h}$. ((a)-(c)) Immunofluorescent microscopic analysis. The original magnification of the images was 200x. Merged images with DAPI-stained nuclei are shown. (d) Western blot analysis of the EndMT. HMVEC were stimulated with the triple cytokine mixture in the presence or absence of AcSDKP for $72 \mathrm{~h}$. The cells were harvested, and the proteins were immunoblotted onto PVDF membranes. Chemiluminescence-detected bands were visualized. $n=2$ in each group. GAPDH was used as the loading control.

the AcSDKP concentration to the creatinine concentration in urine exhibited a trend similar to that of the plasma AcSDKP levels, except that the urinary AcSDKP levels of diabetic mice were significantly lower than those of control mice (Figure 3(b)). TA-606 treatment in diabetic mice did not alter the level of AcSDKP either in plasma or in urine (Figures 3(a) and 3(b)). There was no correlation between the plasma AcSDKP concentration and the glomerular surface area in the diabetic mice (Figure 3(c)). In contrast, we found a negative correlation between the plasma concentration of AcSDKP and the mesangial area (Figure 3(d)) or the relative fibrotic area of the kidneys (Figure 3(e)).

3.3. AcSDKP Inhibited EndMT. An analysis of cells undergoing EndMT, which were identified by double-labeling with FSP1 and CD31 antibodies [FSP1(+); CD31(+)] or with $\alpha$ SMA and CD31 antibodies $[\alpha \operatorname{SMA}(+)$; CD $31(+)]$, showed that the diabetic kidneys contained significantly more cells undergoing EndMT than did the control kidneys (Figures 4(a), 4(b), $4(\mathrm{f}), 4(\mathrm{~g}), 4(\mathrm{k})$, and 4(l)). Imidapril treatment decreased the number of FSP1(+); CD31(+) cells but did not affect the number of $\alpha \operatorname{SMA}(+)$; CD31 $(+)$ cells compared to the untreated diabetic mice (Figures 4(b), 4(c), 4(g), 4(h), 4(k), and 4(l)). Imidapril+AcSDKP combination therapy nearly completely inhibited the induction of cells undergoing EndMT (Figures 4(b), 4(d), 4(g), 4(i), 4(k), and 4(l)). However, TA-606 treatment did not reduce the number of FSP1(+); CD31(+) cells; furthermore, the number of $\alpha \operatorname{SMA}(+)$; CD31(+) cells was increased by TA-606 treatment relative to the diabetic mice (Figures 4(b), 4(e), 4(g), 4(j), 4(k), and 4(l)).

When HMVEC were stimulated with a triple mixture of cytokines (TGF- $\beta 2$, IL- $1 \beta$, and TNF- $\alpha$ ), the expression of the endothelial marker CD31 or VE-cadherin was suppressed; the expression of the mesenchymal marker FSP1 or SM22 $\alpha$ was induced, suggesting induction of EndMT (Figure 5). AcSDKP preincubation inhibited cytokines-stimulated EndMT associated with the suppression of smad3 phosphorylation (Figure 5).

3.4. Endogenous Antifibrosis Program by AcSDKP through FGF Receptor. Chen et al. [19] reported that FGF receptormediated induction of microRNA let-7 family members, which exhibits kidney protective roles $[17,18]$, acts as negative regulators of the EndMT program via inhibition of the TGF$\beta$ signaling pathway [19]. FGF receptor phosphorylation and protein levels were suppressed in diabetic kidney [20]; imidapril treatment increased both the phosphorylation and 


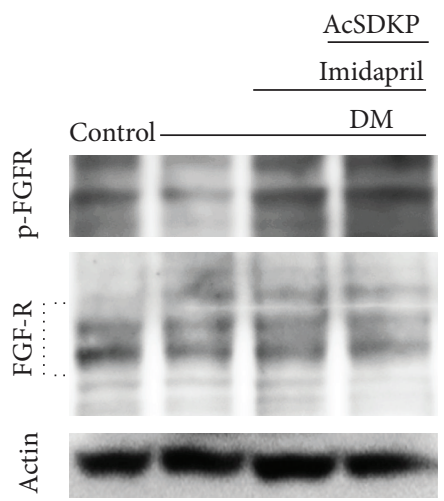

(a)

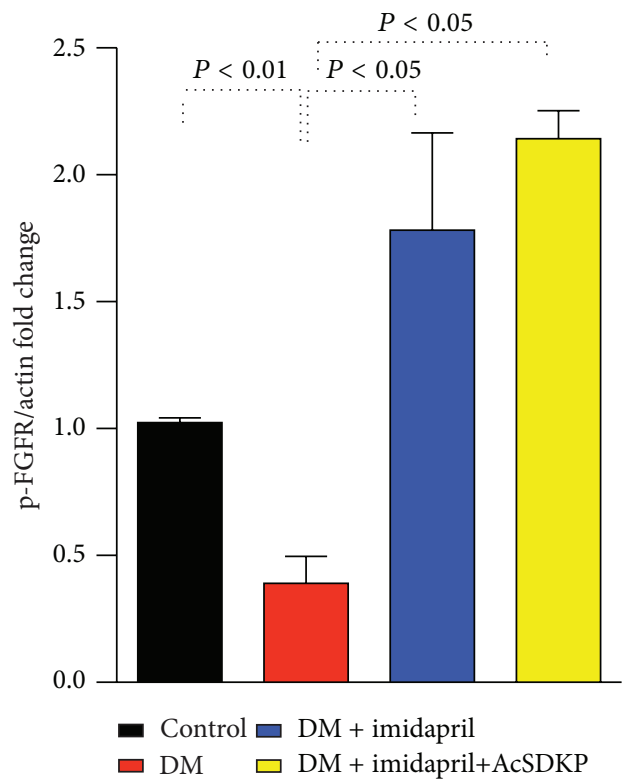

(b)

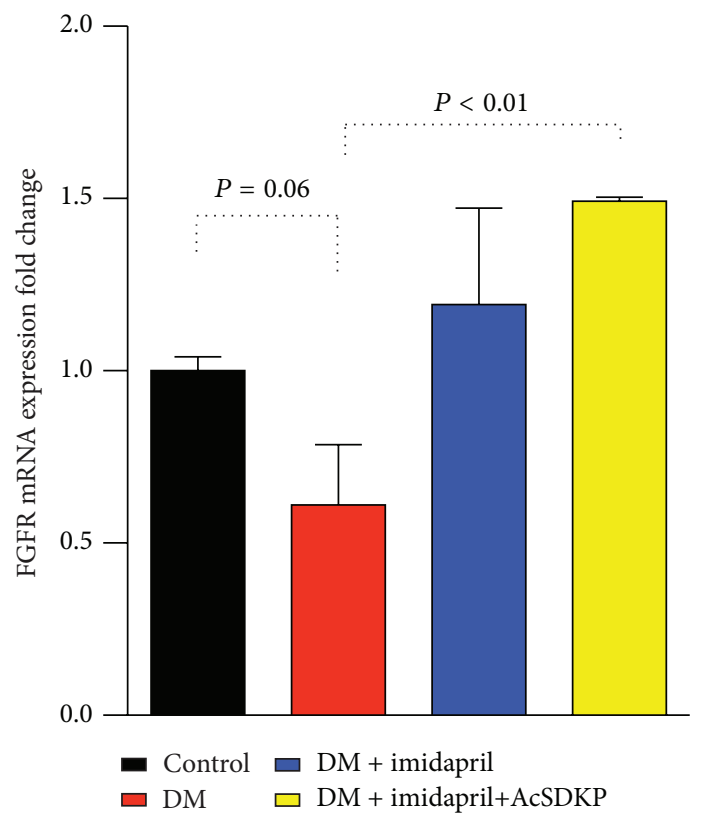

(d)

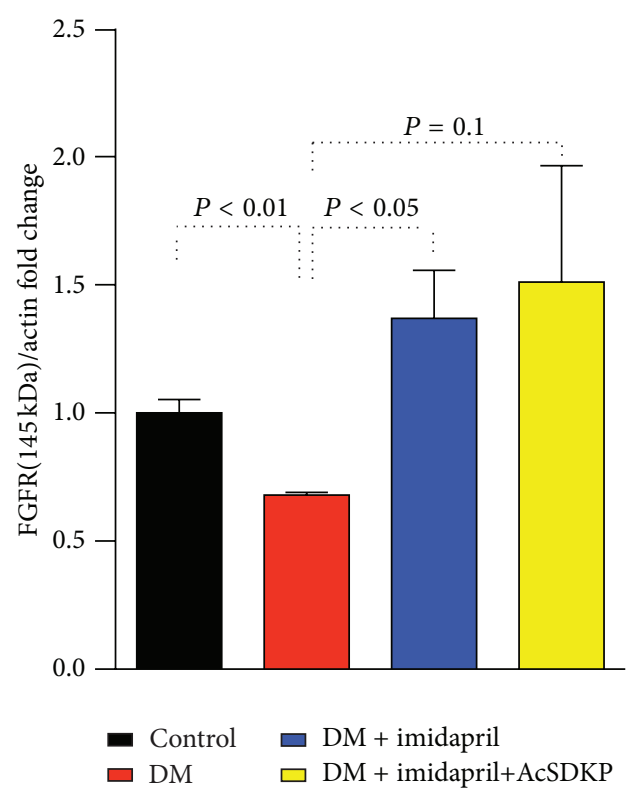

(c)

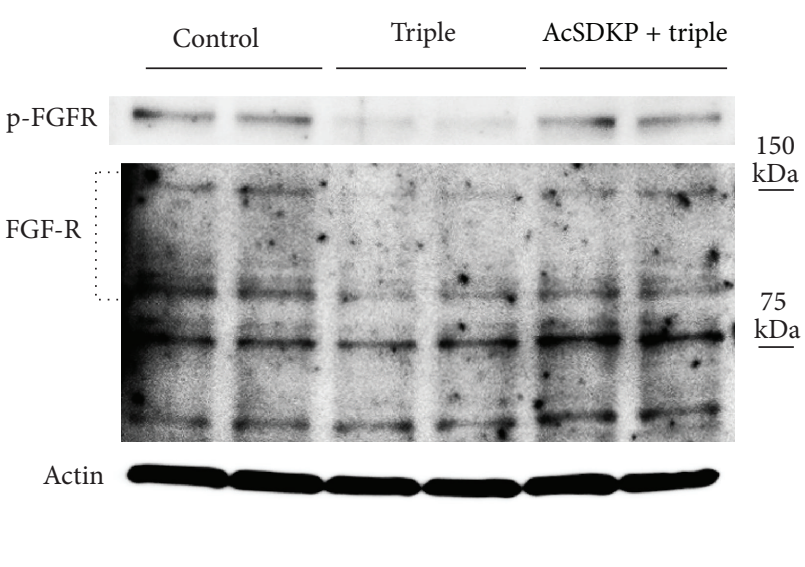

(e)

Figure 6: Continued. 


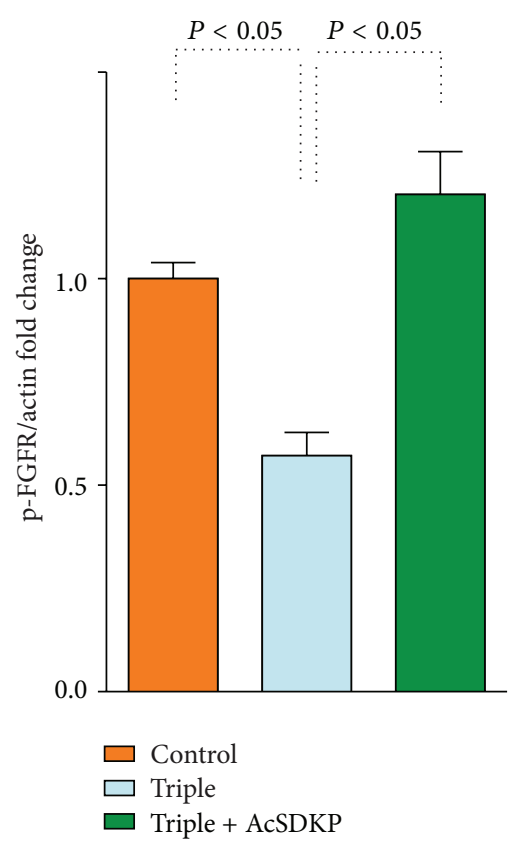

(f)

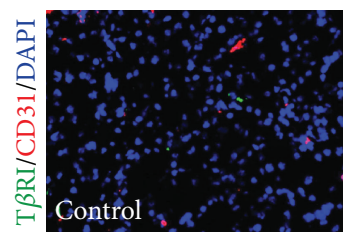

(h)

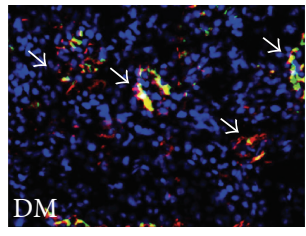

(i)

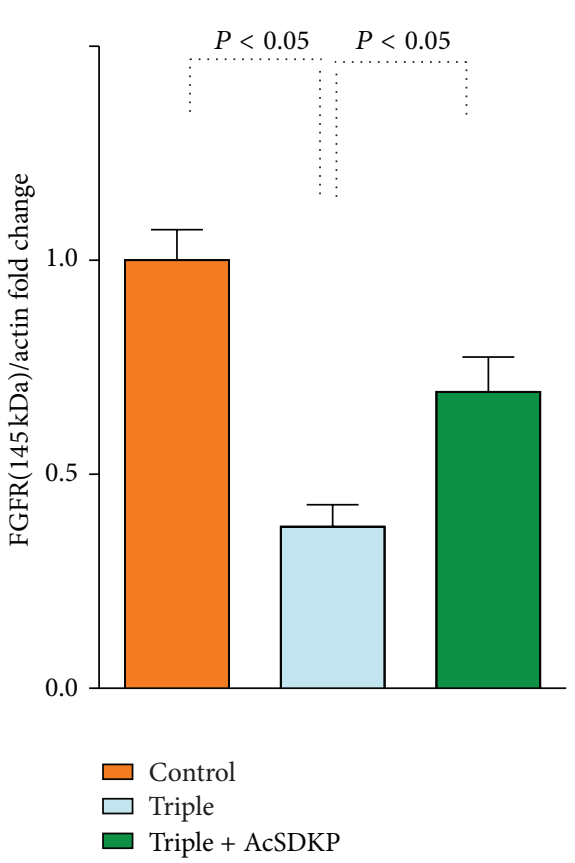

(g)

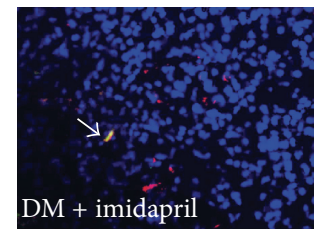

(j)

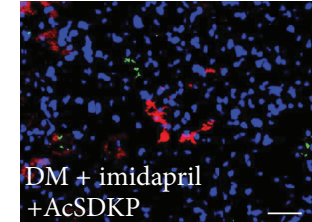

$(\mathrm{k})$

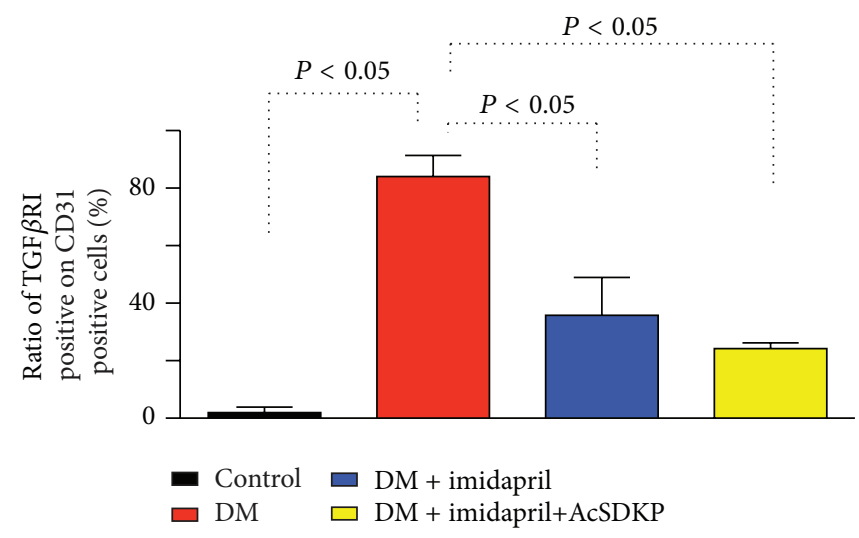

(1)

FIGURE 6: Antifibrotic effect of AcSDKP is associated with restoration of FGFR levels. (a) Western blot analysis of FGF receptor phosphorylation and total protein levels are shown. Actin is shown as a loading control. ((b)-(c)) Densitometric analysis of phospho-FGF receptor and total FGF receptor levels normalized to actin. The results are shown as the relative expression against the control animal values. The data are shown as the mean \pm SEM values $(n=3)$. (d) qPCR analysis for FGF receptor in kidney. The data are shown as the mean \pm SEM values. $n=3$ in each group were analyzed. (e) Western blot analysis for FGF receptor levels and its phosphorylation. The same sample as Figure 5(d) was analyzed for FGF-R status. Representative results $(n=2)$ were shown. ((f), (g)) Densitometric analysis of phospho-FGF receptor and total FGF receptor levels normalized to actin. The results are shown as the relative expression against the control value. The data are shown as the mean \pm SEM values $(n=4)$. TGF- $\beta$ receptor I on endothelial cells in diabetic mice. $((\mathrm{h})-(\mathrm{k}))$. Immunolabeling for TGF- $\beta$ receptor I (T $\beta$ RI) and CD31 in a kidney from indicated group of mice. Arrows indicate cells that are double-labeled for T $\beta$ RI and CD31. Scale bar: $25 \mu \mathrm{m}$. (l) Quantification of cells expressing T $\beta$ RI and CD31. Ratio of T $\beta$ RI positive on all CD31 positive cells in each visual field among 4 images from one animal using fluorescence microscopy and quantified. The data are expressed as the mean \pm SEM values. Diabetes is designated as DM. For all of the groups $n=4$ mice were analyzed. 
protein levels of the FGF receptor in the diabetic kidney (Figures 6(a), 6(b), and 6(c)). A combination therapy exhibited stronger effects on the FGF receptor levels and phosphorylation (Figures 6(a), 6(b), and 6(c)). Such effects of intervention on the FGF receptor in diabetic mice were likely transcription-dependent (Figure 6(d)). When HMVEC was stimulated by mixture of cytokines, the protein levels and phosphorylation of the FGF receptor were significantly diminished; AcSDKP preincubation restored the FGF receptor levels (Figures 6(e), 6(f), and 6(g)).

Our microRNA array analysis of kidney samples revealed that expression of the microRNA mmu-let-7 family was suppressed in the diabetic kidney; we found that expression of most of the microRNA let-7 family members was restored by therapy with the combination of imidapril+AcSDKP (Supplementary Figure 2). qPCR analysis also confirmed that certain sets of microRNA let-7 were indeed inhibited in diabetic mice (Supplementary Figure 2); treatment with the imidapril+AcSDKP combination therapy completely restored their levels. The FGF receptor-microRNA let-7 family axis can suppress TGF- $\beta$ receptor I levels $[19,21]$. In agreement with this report, we observed that endothelial cells in diabetic mice exhibited strong expression of TGF- $\beta$ receptor I; the combination therapy group nearly completely abolished such TGF- $\beta$ receptor I expression on endothelial cells in the diabetic kidney (Figures 6(h), 6(i), 6(j), 6(k), and 6(l)).

\section{Discussion}

4.1. AcSDKP Inhibited EndMT in Fibrotic Kidney in Diabetes. EndMT has emerged as an important source of activated fibroblasts or myofibroblasts [1, 2, 22-24]. The EndMT has been shown to be associated with glomerulosclerosis in early diabetic kidney disease and tubulointerstitial fibrosis in a chronic type 1 diabetes kidney disease model [25]. The TGF$\beta$-induced Smad signaling pathway plays an essential role in the EndMT [26]. In our analysis, AcSDKP inhibited both EndMT in diabetic kidney and in vitro culture cells associated with the inhibition of TGF- $\beta /$ Smad signal transduction. It needs to be mentioned that we rather focused on EndMT in our analysis; there is a possibility that AcSDKP inhibits other fibroblast activation pathways, as reported elsewhere [27]. Also anti-inflammatory, antiapoptotic, and enhanced normal angiogenesis pathways would be contributed in the beneficial effects of AcSDKP [3].

4.2. Two Catalytic Sites of ACE and Endogenous Antifibrotic Program via AcSDKP. Mammalian ACE has two catalytic sites, the $\mathrm{N}$ - and C-terminal catalytic domains. These two catalytic domains may have different substrate selectivity. Although angiotensin-I can be converted to angiotensin-II by either catalytic domain, the C-terminal domain has a threefold higher affinity for angiotensin-I. Interestingly, only the N-terminal catalytic domain hydrolyzes AcSDKP [3]. Notably, each ACE-I exhibits a distinct affinity for one of the catalytic domains; for example, captopril exhibits a higher affinity for the $\mathrm{N}$-terminal catalytic domain. Li et al. recently reported that mice deficient in the $\mathrm{N}$-terminal catalytic domain of ACE exhibited an antifibrotic effect because of the accumulation of AcSDKP [28], which reveals the importance of the N-terminal domain for the antifibrotic activity of ACEI [29-32].

4.3. AcSDKP Stimulates Antifibrotic Program. In our analysis, the concentration of AcSDKP was negatively associated with mesangial expansion and kidney fibrosis. Moreover, we found that endogenous AcSDKP levels were lower in the urine of diabetic animals with fibrotic kidneys. Similar to this observation, suppressed levels in other antifibrotic molecules, such as bone morphogenic protein 7 or its receptor-mediated signaling, in fibrotic kidney diseases have been reported elsewhere [33]. Apart from diabetic kidney disease model, the association between the levels of AcSDKP, other fibrotic kidney disease, and human kidney diseases needs further investigation. These results suggest that high intrarenal ACE activity in the diabetic kidney reduced the level of endogenous AcSDKP; this reduction of the antifibrotic peptide AcSDKP accelerated the fibrotic process in the kidney because of the imbalance between profibrotic and antifibrotic molecules. The antifibrotic/anti-EndMT effects of AcSDKP were associated with restoration of the FGF receptor's levels and associated induction of microRNA let-7. Regard with this, microRNA let-7 family has been shown to protect kidney from fibrotic stimuli $[17,18]$.

\section{Conclusion}

In conclusion, AcSDKP is potentially a valuable endogenous antifibrotic molecule that inhibits the EndMT and restores the expression of the let-7 microRNA family through FGFR restoration at least in part. AcSDKP may therefore be useful for the clinical therapy for kidney fibrosis in diabetes.

\section{Conflict of Interests}

The authors declare that there is no conflict of interests regarding the publication of this paper.

\section{Acknowledgments}

This work was supported primarily by a Grant from the Japan Society for the Promotion of Science to Takako Nagai with Keizo Kanasaki (24659264), research grants from the Japan Research Foundation for Clinical Pharmacology to Keizo Kanasaki (2011), and Takeda visionally research grant to Keizo Kanasaki (2013). Additionally, this work was partially supported by Grants from the Japan Society for the Promotion of Science to Munehiro Kitada (24790329), Munehiro Kitada (24591218) and Daisuke Koya (25282028 and 25670414), and Keizo Kanasaki (23790381), and by Grants for Promoted Research to Keizo Kanasaki (S2011-1 and S2012-5) from Kanazawa Medical University. The authors declare that there is no financial conflict of interests. Keizo Kanasaki and Daisuke Koya received lecture fees from Mitsubishi Tanabe Pharma. Mitsubishi Tanabe Pharma donated to Kanazawa 
Medical University; the donation was not directly associated with this project.

\section{References}

[1] K. Kanasaki, G. Taduri, and D. Koya, "Diabetic nephropathy: the role of inflammation in fibroblast activation and kidney fibrosis," Frontiers in Endocrinology, vol. 4, article 7, 2013.

[2] J. He, Y. Xu, D. Koya, and K. Kanasaki, "Role of the endothelialto-mesenchymal transition in renal fibrosis of chronic kidney disease," Clinical and Experimental Nephrology, vol. 17, no. 4, pp. 488-497, 2013.

[3] M. Kanasaki, T. Nagai, M. Kitada, D. Koya, and K. Kanasaki, "Elevation of the antifibrotic peptide $\mathrm{N}$-acetyl-seryl-aspartyllysyl-proline: a blood pressure-independent beneficial effect of angiotensin I-converting enzyme inhibitors," Fibrogenesis and Tissue Repair, vol. 4, no. 1, article 25, 2011.

[4] K. Kanasaki, D. Koya, T. Sugimoto, M. Isono, A. Kashiwagi, and M. Haneda, "N-acetyl-seryl-aspartyl-lysyl-proline inhibits TGF- $\beta$ mediated plasminogen activator inhibitor-1 expression via inhibition of Smad pathway in human mesangial cells," Journal of the American Society of Nephrology, vol. 14, no. 4, pp. 863-872, 2003.

[5] K. Shibuya, K. Kanasaki, M. Isono et al., "N-acetyl-serylaspartyl-lysyl-proline prevents renal insufficiency and mesangial matrix expansion in diabetic db/db mice," Diabetes, vol. 54, no. 3, pp. 838-845, 2005.

[6] M. Omata, H. Taniguchi, D. Koya et al., "N-acetyl-serylasparlyl-lysyl-proline ameliorates the progression of renal dysfunction and fibrosis in WKY rats with established antiglomerular basement membrane nephritis," Journal of the American Society of Nephrology, vol. 17, no. 3, pp. 674-685, 2006.

[7] J.-M. Liu, F. Lawrence, M. Kovacevic et al., "The tetrapeptide AcSDKP, an inhibitor of primitive hematopoietic cell proliferation, induces angiogenesis in vitro and in vivo," Blood, vol. 101, no. 8, pp. 3014-3020, 2003.

[8] D. Wang, O. A. Carretero, X.-Y. Yang et al., "N-acetyl-serylaspartyl-lysyl-proline stimulates angiogenesis in vitro and in vivo," American Journal of Physiology, vol. 287, no. 5, pp. H2099H2105, 2004.

[9] Y. Fromes, J.-M. Liu, M. Kovacevic, J. Bignon, and J. WdzieczakBakala, "The tetrapeptide acetyl-serine-aspartyl-lysine-proline improves skin flap survival and accelerates wound healing," Wound Repair and Regeneration, vol. 14, no. 3, pp. 306-312, 2006.

[10] T. Huff, C. S. G. Müller, A. M. Otto, R. Netzker, and E. Hannappel, " $\beta$-thymosins, small acidic peptides with multiple functions," The International Journal of Biochemistry and Cell Biology, vol. 33, no. 3, pp. 205-220, 2001.

[11] V. Koutrafouri, L. Leondiadis, K. Avgoustakis et al., "Effect of thymosin peptides on the chick chorioallantoic membrane angiogenesis model," Biochimica et Biophysica Acta, vol. 1568, no. 1, pp. 60-66, 2001.

[12] D. Philp, T. Huff, Y. S. Gho, E. Hannappel, and H. K. Kleinman, "The actin binding site on thymosin beta4 promotes angiogenesis," The FASEB Journal, vol. 17, no. 14, pp. 2103-2105, 2003.

[13] K. M. Malinda, A. L. Goldstein, and H. K. Kleinman, "Thymosin $\beta 4$ stimulates directional migration of human umbilical vein endothelial cells," The FASEB Journal, vol. 11, no. 6, pp. 474-481, 1997.
[14] N. Smart, C. A. Risebro, A. A. D. Melville et al., "Thymosin $\beta 4$ induces adult epicardial progenitor mobilization and neovascularization," Nature, vol. 445, no. 7124, pp. 177-182, 2007.

[15] H. Sugimoto, G. Grahovac, M. Zeisberg, and R. Kalluri, "Renal fibrosis and glomerulosclerosis in a new mouse model of diabetic nephropathy and its regression by bone morphogenic protein-7 and advanced glycation end product inhibitors," Diabetes, vol. 56, no. 7, pp. 1825-1833, 2007.

[16] Y. Hashimoto, R. Ohashi, Y. Kurosawa et al., "Pharmacologic profile of TA-606, a novel angiotensin II-receptor antagonist in the rat," Journal of Cardiovascular Pharmacology, vol. 31, no. 4, pp. 568-575, 1998.

[17] E. P. Brennan, K. A. Nolan, E. Borgeson et al., "Lipoxins attenuate renal fibrosis by inducing let-7c and suppressing TGFbetaR1," Journal of the American Society of Nephrology, vol. 24, pp. 627-637, 2013.

[18] B. Wang, J. C. Jha, S. Hagiwara et al., “Transforming growth factor-betal-mediated renal fibrosis is dependent on the regulation of transforming growth factor receptor 1 expression by let-7b," Kidney International, vol. 85, pp. 352-361, 2014.

[19] P. Y. Chen, L. Qin, C. Barnes et al., "FGF regulates TGFbeta signaling and endothelial-to-mesenchymal transition via control of let-7 miRNA expression," Cell Reports, vol. 2, pp. 1684-1696, 2012.

[20] M. F. Cheng, L. J. Chen, M. C. Wang, C. T. Hsu, and J. T. Cheng, "Decrease of FGF receptor, (FGFR) and interstitial fibrosis in the kidney of streptozotocin-induced diabetic rats," Hormone and Metabolic Research, vol. 46, no. 1, pp. 1-7, 2014.

[21] G. Tzur, A. Israel, A. Levy et al., "Comprehensive gene and microRNA expression profiling reveals a role for microRNAs in human liver development," PLoS ONE, vol. 4, no. 10, Article ID e7511, 2009.

[22] E. M. Zeisberg, S. Potenta, L. Xie, M. Zeisberg, and R. Kalluri, "Discovery of endothelial to mesenchymal transition as a source for carcinoma-associated fibroblasts," Cancer Research, vol. 67, no. 21, pp. 10123-10128, 2007.

[23] E. M. Zeisberg, S. E. Potenta, H. Sugimoto, M. Zeisberg, and R. Kalluri, "Fibroblasts in kidney fibrosis emerge via endothelialto-mesenchymal transition," Journal of the American Society of Nephrology, vol. 19, no. 12, pp. 2282-2287, 2008.

[24] E. M. Zeisberg, O. Tarnavski, M. Zeisberg et al., "Endothelialto-mesenchymal transition contributes to cardiac fibrosis," Nature Medicine, vol. 13, no. 8, pp. 952-961, 2007.

[25] J. Li, X. Qu, and J. F. Bertram, "Endothelial-myofibroblast transition contributes to the early development of diabetic renal interstitial fibrosis in streptozotocin-induced diabetic mice," The American Journal of Pathology, vol. 175, no. 4, pp. 1380-1388, 2009.

[26] X. M. Meng, A. C. Chung, and H. Y. Lan, "Role of the TGFbeta/BMP-7/Smad pathways in renal diseases," Clinical Science, vol. 124, pp. 243-254, 2013.

[27] V. S. LeBleu, G. Taduri, J. O’Connell et al., "Origin and function of myofibroblasts in kidney fibrosis," Nature Medicine, vol. 19, pp. 1047-1053, 2013.

[28] P. Li, H. D. Xiao, J. Xu et al., "Angiotensin-converting enzyme Nterminal inactivation alleviates bleomycin-induced lung injury," The American Journal of Pathology, vol. 177, no. 3, pp. 1113-1121, 2010.

[29] C. Junot, M.-F. Gonzales, E. Ezan et al., "RXP 407, a selective inhibitor of the $\mathrm{N}$-domain of angiotensin I-converting enzyme, blocks in vivo the degradation of hemoregulatory peptide 
acetyl-Ser-Asp-Lys-Pro with no effect on angiotensin I hydrolysis," Journal of Pharmacology and Experimental Therapeutics, vol. 297, no. 2, pp. 606-611, 2001.

[30] G. Vazeux, J. Cotton, P. Cuniasse, and V. Dive, "Potency and selectivity of RXP407 on human, rat, and mouse angiotensinconverting enzyme," Biochemical Pharmacology, vol. 61, no. 7, pp. 835-841, 2001.

[31] W. L. Kröger, R. G. Douglas, H. G. O’Neill, V. Dive, and E. D. Sturrock, "Investigating the domain specificity of phosphinic inhibitors RXPA380 and RXP407 in angiotensin-converting enzyme," Biochemistry, vol. 48, no. 35, pp. 8405-8412, 2009.

[32] C. S. Anthony, H. R. Corradi, S. L. U. Schwager et al., "The N domain of human angiotensin-I-converting enzyme: the role of $\mathrm{N}$-glycosylation and the crystal structure in complex with an $\mathrm{N}$ domain-specific phosphinic inhibitor, RXP407," The Journal of Biological Chemistry, vol. 285, no. 46, pp. 35685-35693, 2010.

[33] H. Sugimoto, V. S. LeBleu, D. Bosukonda et al., "Activin-like kinase 3 is important for kidney regeneration and reversal of fibrosis," Nature Medicine, vol. 18, no. 3, pp. 396-404, 2012. 


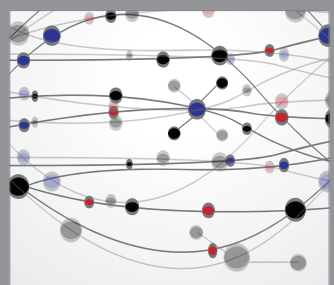

The Scientific World Journal
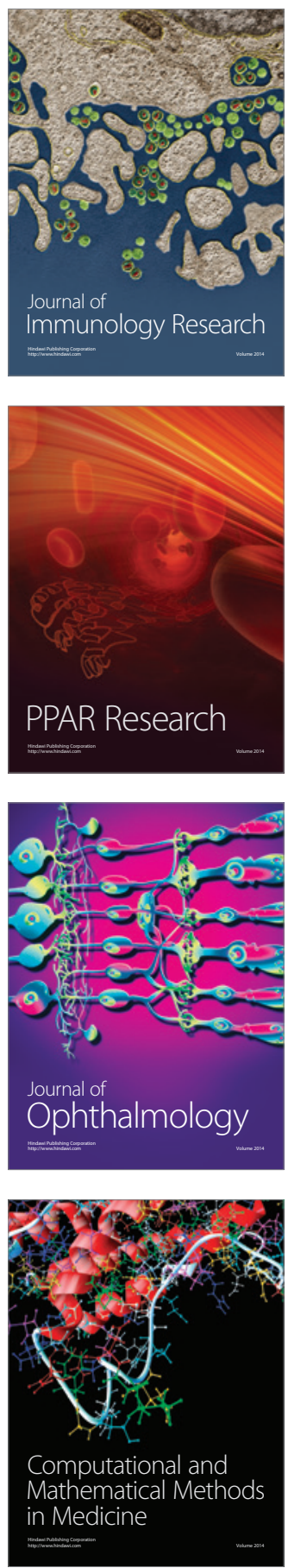



Gastroenterology

Research and Practice
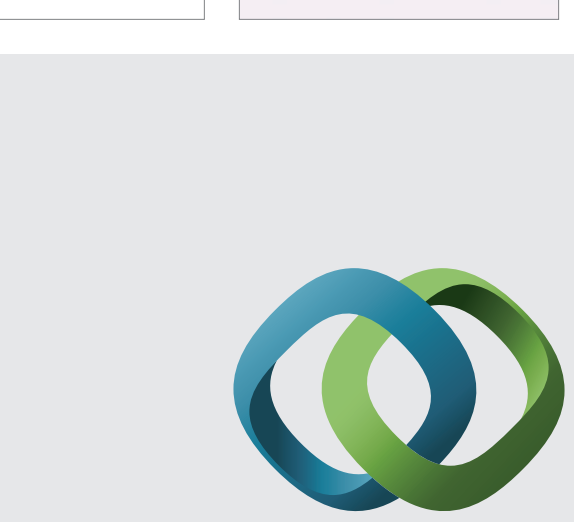

\section{Hindawi}

Submit your manuscripts at

http://www.hindawi.com
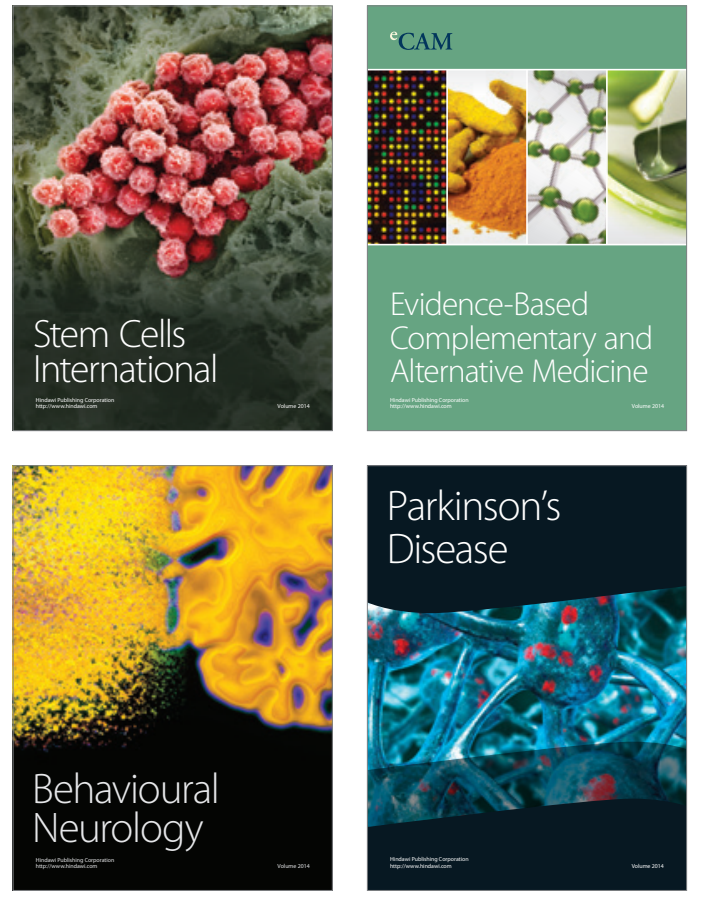
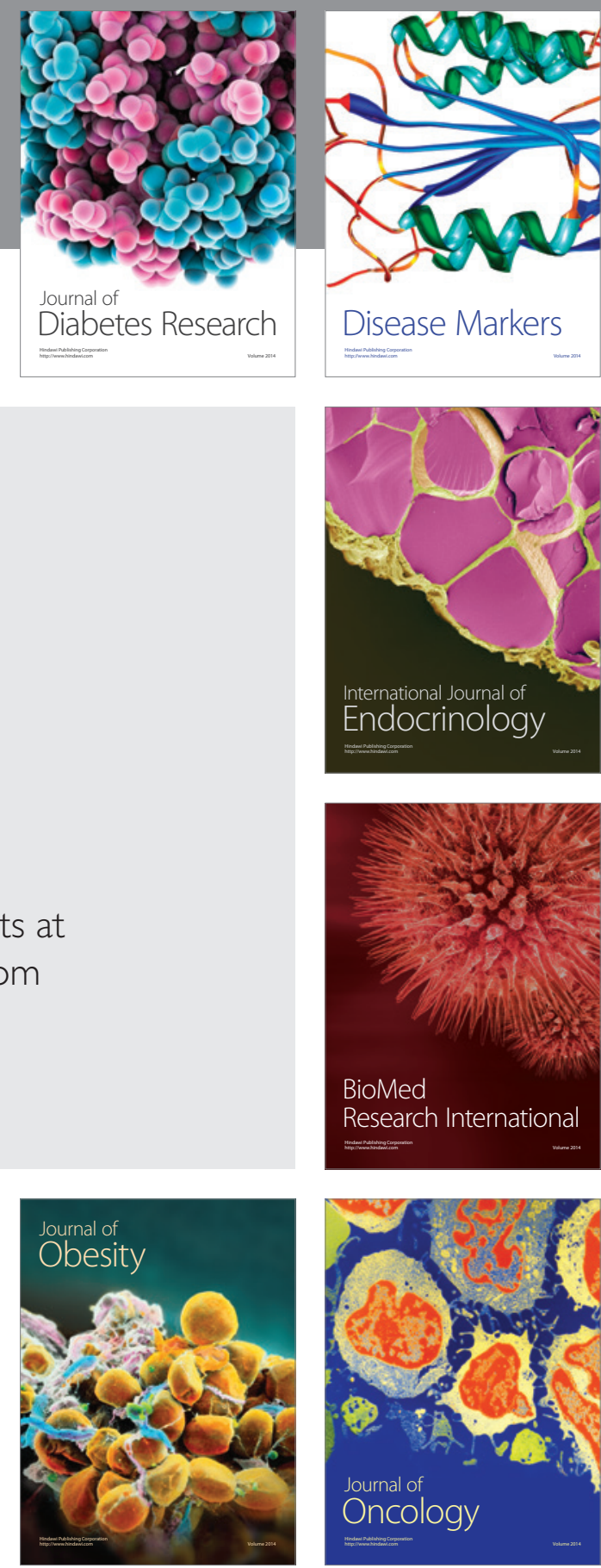

Disease Markers
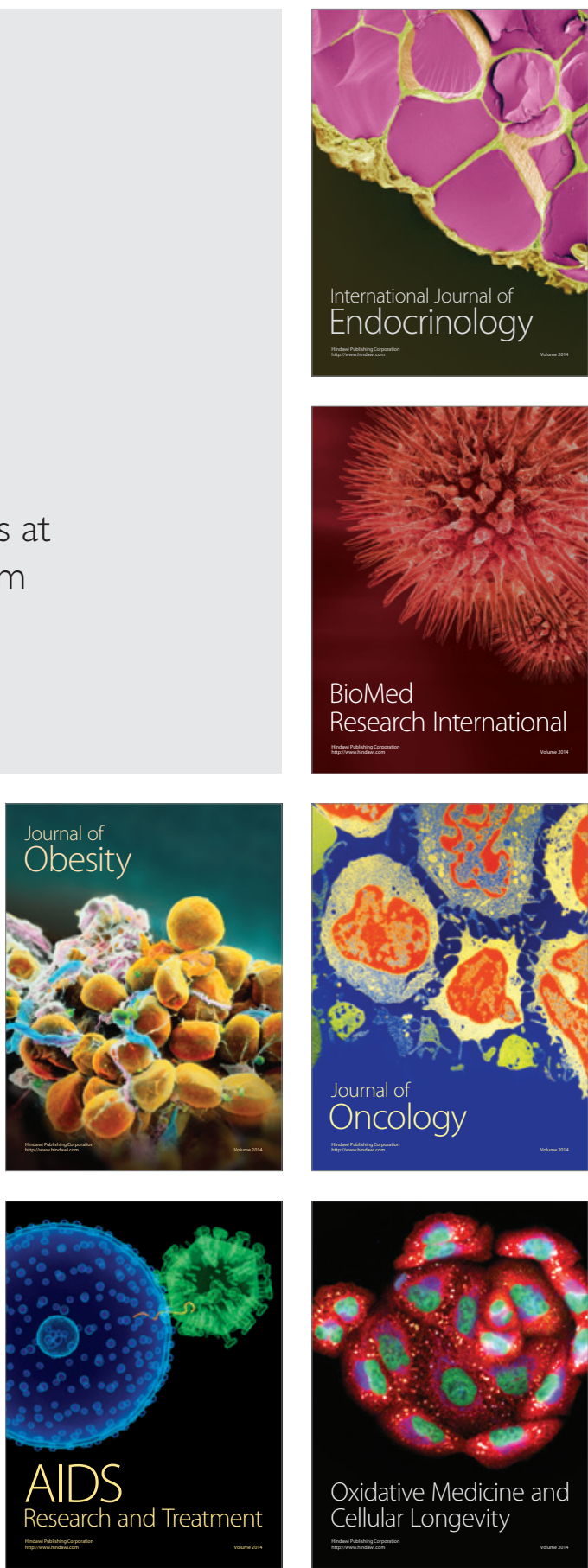